\title{
Investigation of possible molecular mechanisms underlying the regulation of adhesion in Vibrio alginolyticus with comparative transcriptome analysis
}

\author{
Wendi Kong $\cdot$ Lixing Huang $\cdot$ Yongquan Su • \\ Yingxue Qin · Ying Ma $\cdot$ Xiaojin Xu • \\ Mao Lin · Jiang Zheng $\cdot$ Qingpi Yan
}

Received: 27 January 2015/ Accepted: 19 February 2015/Published online: 1 March 2015

(C) The Author(s) 2015. This article is published with open access at Springerlink.com

\begin{abstract}
Adhesion capability to fish mucus, which can be affected by environmental conditions, is considered to be a key virulence factor of Vibrio alginolyticus although the molecular mechanism is still unclear. In the present study, V. alginolyticus was treated with stress conditions including $\mathrm{Cu}^{2+}(50 \mathrm{mg} /$ $\mathrm{L}), \mathrm{Pb}^{2+}(100 \mathrm{mg} / \mathrm{L}), \mathrm{Hg}^{2+}(50 \mathrm{mg} / \mathrm{L})$ and low $\mathrm{pH}$ (pH 5). We found these stress treatments were capable of reducing the adhesion of $V$. alginolyticus, while the expression levels of multiple genes were significantly changed according to the results of high throughput sequencing. The expression of randomly selected genes was confirmed by QPCR, which reinforced the reliability of the sequencing data. Ontology assignments and KEGG pathway analysis indicated that
\end{abstract}

L. Huang co-first author.

Electronic supplementary material The online version of this article (doi:10.1007/s10482-015-0411-9) contains supplementary material, which is available to authorized users.

W. Kong · L. Huang · Y. Qin · Y. Ma ·

X. Xu · M. Lin · J. Zheng · Q. Yan $(\bowtie)$

Key Laboratory of Healthy Mariculture for the East China

Sea, Ministry of Agriculture, Fisheries College, Jimei

University, Xiamen 361021, Fujian, People's Republic of

China

e-mail: yanqp@jmu.edu.cn

Y. Su

College of Ocean \& Earth Sciences, Xiamen University, Xiamen 361005, Fujian, People's Republic of China stress treatments affect pathways that may be related to adhesion. Our results identified genes which might play a key role in the adhesion process of $V$. alginolyticus, which could lay a foundation for further functional analysis of these genes in the process of adhesion. As these genes were sensitive to environmental factors, this may explain why the adhesion process can be influenced by environmental factors.

Keywords Vibrio alginolyticus · Adhesion · Transcriptome

\section{Introduction}

Vibrio alginolyticus, an important opportunistic pathogen for marine organisms (Carli et al. 1993), is associated with epidemic vibriosis which causes mass mortality to many marine cultured animals, including fish (Lee et al. 1995; Balebona et al. 1998), shellfish (Liu et al. 2001), shrimp (Lee et al. 1996) and coral reefs (Xie et al. 2013). V. alginolyticus is also a pathogenic bacterium for people who are in contact with seafood, which may lead to otitis and wound infections (Lin et al. 2001). In recent years, $V$. alginolyticus has been frequently found to be the cause of disease in marine cultured fish in China and has resulted in considerable losses (Wang et al. 2001).

Bacterial adhesion to fish tissue surfaces is an important step in the initial stage of infection (Thune et al. 1993). Intestines and injured skin are considered 
to be the portals of entry for Vibrio species into fish (Chen et al. 2008). A mucous layer can be found covering the intestine and skin of fish. Bacterial adherence to the mucus is an essential requirement for infection by different pathogens (Speare et al. 1992). Thus, the ability to adhere to mucus is considered to be a crucial bacterial virulence mechanism (Chen et al. 2008). Bacterial adhesion is influenced by bacterial factors, the adhesion substrate and environmental factors (Yan et al. 2007). In our previous research, we detected effects of environmental factors (including $\mathrm{Cu}^{2+}, \mathrm{Pb}^{2+}, \mathrm{Hg}^{2+}$, low $\mathrm{pH}$, high $\mathrm{pH}$, low salinity, high salinity, low temperature, and high temperature) on $V$. alginolyticus adhesion. Our results showed that $\mathrm{Cu}^{2+}$, $\mathrm{Pb}^{2+}, \mathrm{Hg}^{2+}$ and low $\mathrm{pH}$ could reduce the adhesion of V. alginolyticus.

As an important environmental factor, $\mathrm{pH}$ has a great effect on bacterial attachment (Balebona et al. 1995; Yan et al. 2007). Additional research in our laboratory indicated that low $\mathrm{pH}$ could reduce the adhesion of $V$. alginolyticus to skin mucus of large yellow crokers (data not shown). Moreover, our research also indicated that heavy metals, including $\mathrm{Cu}^{2+}, \mathrm{Pb}^{2+}$, and $\mathrm{Hg}^{2+}$, could reduce the adhesion of $V$. alginolyticus to skin mucus of large yellow crokers at different concentrations (Fig. S1).

Although several genes have been shown to be associated with vibrial adhesion (Qin et al. 2013), the mechanism of bacterial adhesion is still unclear. Additionally, little is known about how the adhesion process can be influenced by environmental factors. A powerful approach to determine how an organism responds to a particular abiotic condition is to determine how it changes the expression of its genes (Simon et al. 2013). Traditional techniques are time consuming and impractical for large scale detection of hundreds of genes. Instead, high throughput sequencing has been widely used in bacterial transcriptome profiling, which can simultaneously determine expression levels for large numbers of genes in a single experiment and help to gain insight into molecular mechanisms in bacteria (Xu et al. 2003; Bisharat et al. 2013; Lenz et al. 2011; Sharma et al. 2010; Arnvig et al. 2011; Yang et al. 2009). Although the complete genome of $V$. alginolyticus has been sequenced, the transcriptome analysis of $V$. alginolyticus has not yet been reported.

In the present research, we present the first deep sequencing study of the transcriptome of $V$. alginolyticus cultured under normal and stress conditions such as $\mathrm{Cu}$, $\mathrm{Pb}, \mathrm{Hg}$ and low $\mathrm{pH}$. The objectives of this study were to: (1) determine a broad spectrum of expression of genes associated with bacterial adhesion in order to offer new clues for further understanding of the mechanism(s) underlying the regulation of adhesion in V. alginolyticus; (2) to gain further understanding of how the adhesion process can be influenced by environmental factors.

\section{Materials and methods}

Bacterial samples and culture conditions

Vibrio alginolyticus (ND-01) was previously isolated from a naturally infected large yellow croaker by our laboratory and confirmed as pathogenic by artificial infection (Yan et al. 2001). The sample was stored at $-80{ }^{\circ} \mathrm{C}$ in physiological saline with $10 \%$ glycerol. Bacteria were cultured on tryptic soy agar (TSA) supplemented with $2 \% \mathrm{NaCl}$ at $28{ }^{\circ} \mathrm{C}$. Bacteria were challenged by chemical stresses including $\mathrm{Cu}^{2+}$ $\left(50 \mathrm{mg} / \mathrm{L} \mathrm{CuSO}_{4} \cdot 5 \mathrm{H}_{2} \mathrm{O}\right), \mathrm{Pb}^{2+}\left(100 \mathrm{mg} / \mathrm{L}(\mathrm{CH} 3 \mathrm{COO})_{2}\right.$ $\mathrm{Pb}), \mathrm{Hg}^{2+}\left(50 \mathrm{mg} / \mathrm{L} \mathrm{HgCl}_{2}\right)$ and low $\mathrm{pH}$ (HCL was used to lower the $\mathrm{pH}$ to $\mathrm{pH} 5$ ), respectively. These conditions were chosen based on our earlier research, which investigated the effects of these stresses on adhesion at different concentrations Supplementary Fig. 1). The control group was cultured on normal TSA slant $(\mathrm{pH}=7)$. There were three replicates for each of the treatments.

\section{Mucus preparation}

Healthy large yellow croakers were obtained from marine culture-cages, at Ningde in Fujian province of China. Intestinal mucus was prepared using a method modified from one described before (Chen et al. 2008). The intestines were removed and transferred to sterile petri dishes and washed with sterile PBS $(0.01 \mathrm{~mol} / \mathrm{L}$ $\mathrm{pH}$ 7.2). Then the guts were split open with a scalpel. The intestine mucus was harvested by scrapping off the inner surface of the intestines with a plastic spatula to remove the mucus gel layer covering the intestinal lumen and homogenized in PBS. The mucus preparations were centrifuged twice at $20,000 \mathrm{~g}, 4^{\circ} \mathrm{C}$ for $30 \mathrm{~min}$ to remove particulate materials. The final supernatant was filtered through 0.45 and $0.22 \mu \mathrm{m}$ pore size filters. The mucus samples were adjusted to 
$1 \mathrm{mg}$ protein $/ \mathrm{mL}$ PBS. The protein concentration was determined using the method of Bradford (Bradford et al. 1976).

In vitro adhesion assay

The bacterial adhesion assay was conducted following the method described by Yan et al. (2006). Briefly, $50 \mu \mathrm{L}$ of mucus suspension were evenly spread on a $22 \times 22 \mathrm{~mm}$ area of glass slides and fixed by methanol for $20 \mathrm{~min}$, after the mucus was dry. $V$. alginolyticus $\mathrm{ND}-01$ was grown in TSB liquid medium supplemented with $2 \% \mathrm{NaCl}$ overnight. Then, the bacteria were collected by centrifugation and suspended in PBS. The suspensions were adjusted to $10^{8} \mathrm{CFU} / \mathrm{ml}$ according to the values of $\mathrm{OD}_{560}$ (based on a linear relationship between $\mathrm{OD}_{560}$ values and the CFU values of the bacterial suspension). Then, $1 \mathrm{~mL}$ aliquots of bacterial suspensions $\left(10^{8} \mathrm{CFU} / \mathrm{ml}\right)$ was placed on mucus-coated glass slides, incubated at $25{ }^{\circ} \mathrm{C}$ for $2 \mathrm{~h}$, and then washed thoroughly five times with PBS. Finally, slides were fixed with $4 \%$ methanol for $30 \mathrm{~min}$ and stained with crystal violet for $3 \mathrm{~min}$. After staining, the slide was observed using a microscope and imaged with a digital video camera (magnification, $\times 1000$ ). The number of bacteria was quantified using IPwin software from the images $(\mathrm{n}=3$ slides per condition, 20 fields of view per slide).

Total RNA extraction and cDNA library construction

Head-on comparison of RNA-Seq with microarrays has shown that RNA-Seq has negligible technical variability, making it possible to obtain a reliable estimate of gene expression without replicate analysis (Marioni et al. 2008; Reddy et al. 2012). Therefore, we applied RNA-Seq and conducted the analysis without a replicate. rRNA was removed with a Ribo-Zero rRNA Removal Kit after total RNA was collected from the pooled bacteria. mRNA was disrupted into fragments, which were used for the first-strand cDNA synthesis. The second-strand cDNA was synthesized using buffer, dATPs, dGTPs, dCTPs, dUTPs, RNase H and DNA polymerase I respectively. Short fragments were purified with a QiaQuick PCR extraction kit and resolved with EB buffer for end reparation and adding poly(A). After that, the short fragments were connected with sequencing adapters. Then, the UNG enzyme was used to degrade the second-strand cDNA, and the product was purified using a MiniElute PCR Purification Kit before PCR amplification.

Illumina sequencing and data processing

The amplification products were sequenced using Illumina HiSeq2000. Dirty raw reads which contain adapters, unknown or low quality bases were discarded to obtain clean reads. Clean reads were mapped to the reference genome and gene sequences respectively using SOAP2 ( $\mathrm{Li}$ et al. 2009). Mismatches ( $\leq 5$ bases) were allowed in the alignment. The unigene expression was calculated in RPKM (Reads Per kb per Million reads) method (Mortazavi et al. 2008), which can eliminate the influence of different gene length and sequencing discrepancy on the calculation of gene expression and therefore the difference of gene expression among samples can be compared. Differential expression genes (DEGs) analysis was applied to identify differentially regulated genes (different ratio $\geq 2$ ) between stressed samples and the control, using the two classes unpaired MA-plot-based method to detect and visualize gene expression difference with significant $P$ value $<0.001$.

The data have been deposited in the NCBI Sequence Read Archive (SRA) and can be accessed through accession number SRP049226.

Functional classification and enrichment analysis for DEGs

For DEGs annotation, we used the Blast2GO program to obtain GO annotation of the unigenes. After acquiring the GO annotation for every gene, we used WEGO software to carry out GO functional classification for all genes and understand the distribution of gene functions of the species at the macro level. The calculated $P$ value went through Bonferroni Correction, taking corrected $P$ value $\leq 0.05$ as a threshold. GO terms fulfilling this condition were defined as significantly enriched GO terms in DEGs.

The COG and KEGG pathways annotation was carried out using Blastall software against COG (http:// www.ncbi.nlm.nih.gov/COG) and KEGG (http://www. genome.jp/kegg/) database. Q value was defined to be the FDR analogue of the $P$ value. Pathways with $\mathrm{Q}$ 
value $\leq 0.05$ were regarded as significantly enriched in DEGs.

\section{QPCR assay}

In order to further validate the results of sequencing, expression levels of genes were verified by QPCR $(\mathrm{n}=3)$. QPCR analysis was performed on a Rotorgene6000 Real-Time PCR system (ABI, USA) using SYBR green I fluorescent dye. The reactions were performed in a $10 \mu \mathrm{L}$ volume mix containing $0.2 \mu \mathrm{L}$ SYBR Green I, $5 \mathrm{pmol} / \mathrm{L}$ specific primers and approximately $50 \mathrm{ng}$ cDNA. The cycling parameters were $95{ }^{\circ} \mathrm{C}$ for $10 \mathrm{~min}$, followed by 45 cycles of $95{ }^{\circ} \mathrm{C}$ for $20 \mathrm{~s}, 55{ }^{\circ} \mathrm{C}$ for $20 \mathrm{~s}$, and $72{ }^{\circ} \mathrm{C}$ for $20 \mathrm{~s}$. Threshold cycles and dissociation curves were determined with Rotor-gene6000 software, to confirm that only one PCR product was amplified and detected, and gene expression levels were normalized to 16S RNA (which showed an invariant expression under the experimental conditions). Primer sequences designed using software Primer Premier 5.0 are listed in Table S1.

\section{Data processing}

Results were reported as mean \pm SD The data were statistically analyzed with one-way ANOVA followed by Dunnett's multiple comparison tests via SPSS 13.0 software. A value of $P<0.05$ was used to indicate significant difference.

The Relative Expression Software Tool (REST 2008-version 2) was used to calculate the relative expression of mRNA target genes in real time fluorescence quantitative PCR using the Pair Wise Fixed Reallocation Randomization Test (Pfaffl et al. 2002). The mathematical model used was based on the mean crossing point deviation between the sample and the control group, normalized by the mean crossing point deviation of the reference genes. Specific amplification efficiencies were included in the correction of the quantification ratio. Significant differences between groups were determined by ANOVA followed by the Tukey's LSD.

\section{Results}

Adhesion of $V$. alginolyticus after stress

$V$. alginolyticus ND-01 exhibited variable adhesion to the intestinal mucus of large yellow crokers after stress challenges. The adhesion of the low $\mathrm{pH}$ treated bacteria significantly decreased to $43.4 \%$, while $\mathrm{Cu}^{2+}, \mathrm{Pb}^{2+}$, and $\mathrm{Hg}^{2+}$ treated groups significantly decreased to $62.6,60.7$ and $59.4 \%$, respectively (Table 1).

Mapping of reads and identification of DEGs

To compare the transcriptome profile of stressed groups with the control, RNA sequencing libraries were constructed for $\mathrm{Cu}^{2+}, \mathrm{Pb}^{2+}, \mathrm{Hg}^{2+}$, low $\mathrm{pH}$ treated bacteria and the control. Each library generated about 12.9-13.8 million reads (Table 2), which were mapped to the $V$. alginolyticus E0666 genome sequence (NCBI Reference Sequence: NZ_AMPD000 00000.1). For $\mathrm{Cu}^{2+}, \mathrm{Pb}^{2+}, \mathrm{Hg}^{2+}$, low $\mathrm{pH}$ treated groups and the control, about 87.5, 87.7, 88.4, 88.1 and $87.2 \%$ reads were matched to NCBI annotated gene regions, respectively (GEO database: accession number GSE44215) (Table 2). The distribution of gene coverage among the different groups was also determined (Table S2). There were 4565 protein-coding genes predicted in the genome of $V$. alginolyticus E0666 by genome analysis. In total, 4045 transcripts were identified in this study. With a threshold of more than five reads mapped to the transcripts of a given gene in each sample, expression of a total of 3962 , 3924, 3978, 3987 and 3994 protein-coding genes was

Table 2 Overview of reads distribution

\begin{tabular}{llllll}
\hline Reads (million) & Control & $\mathrm{Cu}$ & $\mathrm{Pb}$ & $\mathrm{Hg}$ & Low $\mathrm{pH}$ \\
\hline Total reads & 13.3 & 12.9 & 13.1 & 13.8 & 13.4 \\
Total mapped reads & 11.6 & 11.3 & 11.5 & 12.1 & 11.4 \\
\hline
\end{tabular}

Table 1 The adhesion capacity to mucus of wild and stressed V. alginolyticus

\begin{tabular}{llllll}
\hline & Control & $\mathrm{Cu}$ & $\mathrm{Pb}$ & $\mathrm{Hg}$ & $\mathrm{Low} \mathrm{pH}$ \\
\hline Cells/vision & $420.0 \pm 46.7$ & $262.9 \pm 29.2^{*}$ & $255.1 \pm 28.4^{*}$ & $249.3 \pm 27.7^{*}$ & $182.4 \pm 20.3^{*}$ \\
\hline${ }^{*} P<0.05$ versus the control group & & &
\end{tabular}


detected in $\mathrm{Cu}^{2+}, \mathrm{Pb}^{2+}, \mathrm{Hg}^{2+}$, low $\mathrm{pH}$ treated groups and the control, respectively.

The R-package DEG-seq was used to identify DEGs. The list of genes with significantly different expression levels was refined using the criterion of $P$ value $\leq 0.001$ in t tests. These analysis finally yield 1637 (177 up regulated and 1460 down regulated), 1085 (74 up and 1011 down), 846 (143 up and 703 down) and 1791 (253 up and 1538 down) DEGs in $\mathrm{Cu}^{2+}, \mathrm{Pb}^{2+}, \mathrm{Hg}^{2+}$, and low $\mathrm{pH}$ treated groups, respectively.

Only one up-regulated gene was found in all four treated groups, while 212 genes were down-regulated in all four treated groups (Table S3). These genes were hierarchically clustered and used to produce a heat map (Fig. 1). The heat map display the alteration trend of these 213 common regulated genes.

\section{Quantitative real-time PCR (QPCR)}

In order to validate the results of sequencing, we performed QPCR on randomly selected DEGs. The results of QPCR matched those of the sequencing: all treatments significantly down-regulated the expression of aotJ, aotM, livM, oppC, oppF, proW, tupA and tupB (Fig. 2). These data reinforced the reliability of the sequencing data.

Gene ontology (GO) assignments of the DEGs

The functions of DEGs were analyzed according to GO, while the number of genes mapped to every term was calculated. According to this analysis, 1278, 848, 672 and 1413 DEGs from $\mathrm{Cu}^{2+}, \mathrm{Pb}^{2+}, \mathrm{Hg}^{2+}$, and low $\mathrm{pH}$ treated groups were categorized into 37 enriched functional groups (Fig. 3).

Analysis of GO categories showed that the functional distribution of the DEGs from each stressed group was similar. In the libraries, most of the corresponding biological process genes were involved in cellular processes, metabolic processes, establishment of localization and localization. Most of the cellular component genes encoded proteins associated with cell, cell part, membrane and membrane part; and
Fig. 1 Hierarchical clustering of commonly changed DEGs. Green and red indicate decreased and increased expression, respectively. Transcripts were clustered by hierarchical clustering using the complete linkage algorithm and Pearson correlation metric in R. The arrow indicates the common downregulated gene

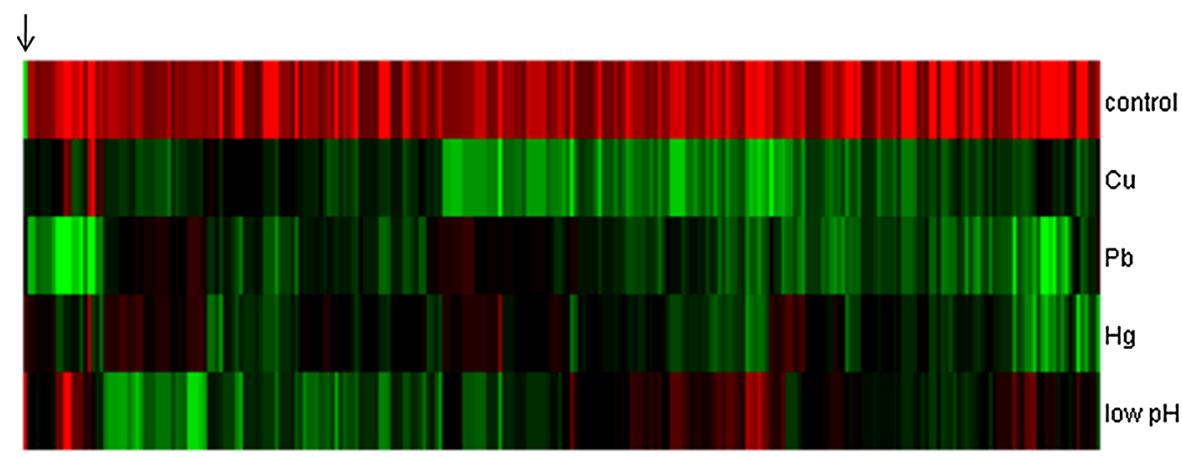



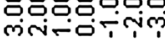

Fig. 2 QPCR analysis of the expression of randomly selected novel genes. Data are presented as mean $\pm \mathrm{SD}$ $(\mathrm{n}=3)$. Means of treatments not sharing a common letter are significantly different at $P<0.05$

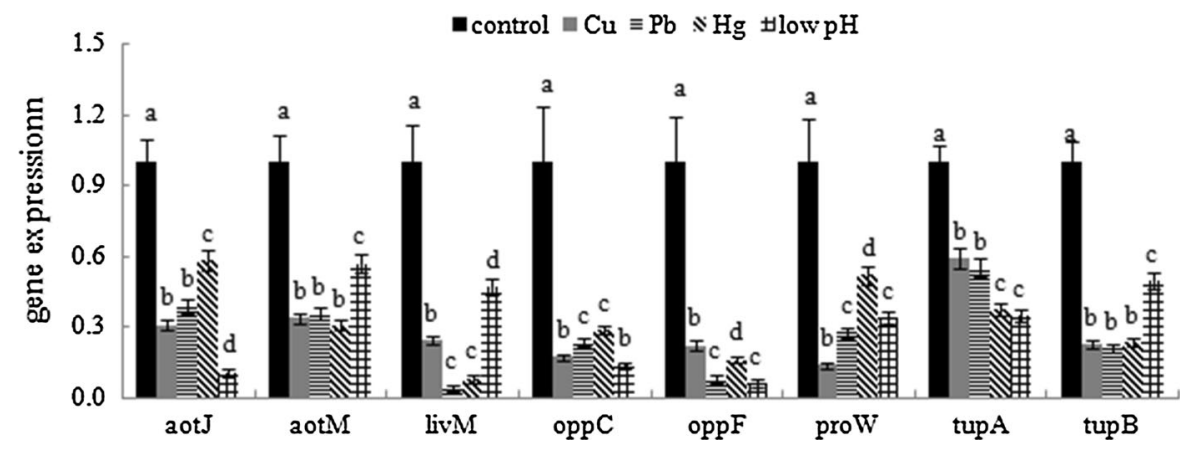




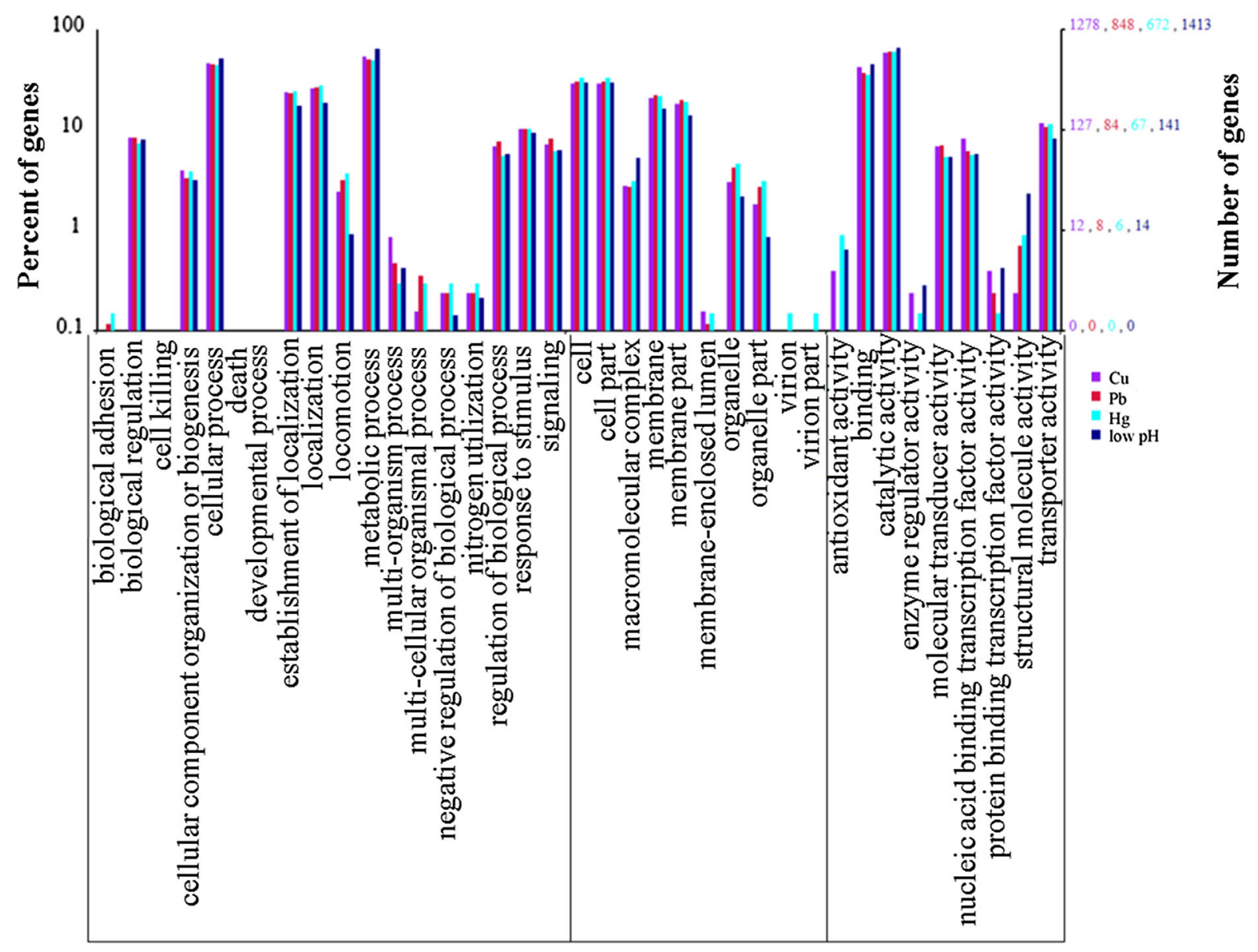

Fig. 3 Functional annotation of DEGs based on known proteins in the database. Each annotated sequence was assigned at least one GO term. GO terms at the second level were

most of the molecular function genes were associated with binding and catalytic activity (Fig. 3).

Clusters of orthologous groups (COG) of DEGs

We also assigned the function of all the DEGs by COG analysis. In the COG functional classification, about $65.3 \%$ of the DEGs could be annotated to 3418 functions involved in 22 COG categories, while no DEG was annotated to "extracellular structures", "nuclear structure", or "cytoskeleton" (Fig. 4). Among the 22 COG categories, the "General function prediction only" cluster represented the largest group (374 genes), followed by the "Amino acid transport and metabolism", "Function unknown" and "Transcription" clusters. The "RNA processing and modification", "Chromatin structure and dynamics" and displayed to classify the results based on their involvement in biological processes, molecular functions, and cellular components

"Cell cycle control, cell division and chromosome partitioning" represented the smallest clusters predicted by COG.

\section{KEGG pathway annotation}

To identify the biological pathways that are active in bacterial adherence, we mapped the DEGs to reference canonical pathways in KEGG.

Using KEGG, DEGs were assigned to 164 KEGG pathways. Those pathways with the greatest representation by DEGs were "ABC transportersystem", "Two-component system", "Glyoxylate and dicarboxylate metabolism" and "Flagellar assembly". These annotations provide a substantial resource for investigating specific processes, functions and pathways during bacteria adherence. 
Fig. 4 Histogram presentation of clusters of orthologous groups (COGs) classification of all-DEGs

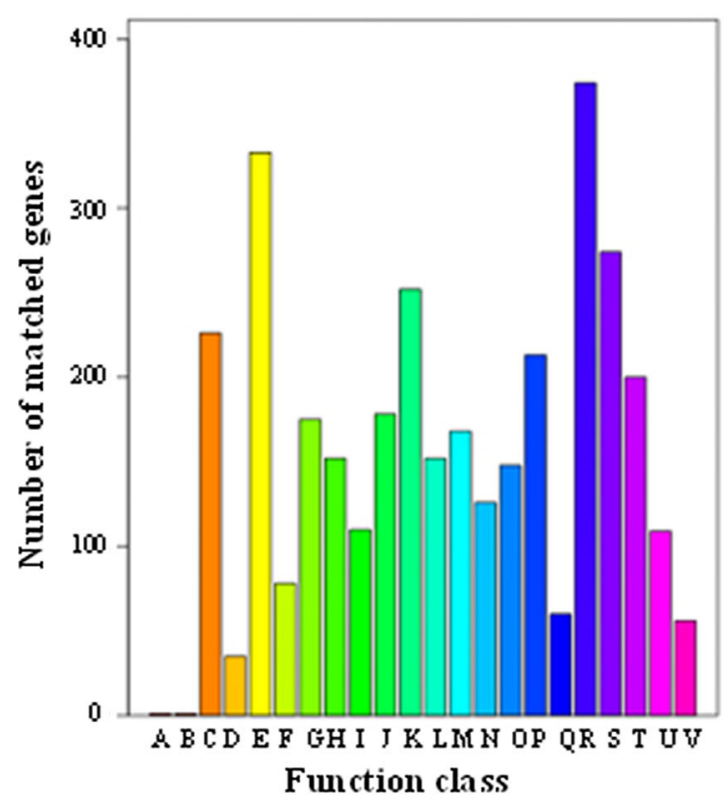

A: RNA processing and modification B: Chromatin structure and dynamics C: Energy production and conversion D: Cell cycle control, cell division, chromosome partitioning

E: Amino acid transport and metabolism F: Nucleotide transport and metabolism G: Carbohydrate transport and metabolism H: Coenzyme transport and metabolism I: Lipid transport and metabolism J: Translation, ribosomal structure and biogenesis

K: Transeription

L.: Replication, recombination and repair M: Cell wallimembrane/envelope biogenesis

N: Cell motility

O: Postranslational modification, protein tumover, chaperones

P: Inorganic ion transport and metabolism Q: Secondary metabolites biosynthesis. transpont and catabolisn

R: General function prediction only S: Function unknown

T: Signal transduction mechanisms U: Intracellular trafticking, socretion, and vesicular transport

V: Defense mechanisms
Among the 164 KEGG pathways, some pathways are known to be closely related to adhesion, for example: "Two-component system", "Bacterial chemotaxis" and "Flagellar assembly". Interestingly, the levels of "Bacterial chemotaxis" genes among the different stressed groups was low $\mathrm{pH}$ treated group $>\mathrm{Cu}^{2+}$ treated group $>\mathrm{Pb}^{2+}$ treated group $>\mathrm{Hg}^{2+}$ treated group, which was consistent with the extent that adhesion was decreased by these conditions.

Other pathways that displayed expression levels consistent with the extent that adhesion decreased in the stressed groups were also observed, although they have not apparently been reported to be associated with the process of adhesion, such as "Metabolic pathways", "Microbial metabolism in diverse environments", "Biosynthesis of secondary metabolites", and "ABC transporter system".

\section{Discussion}

Transcriptome sequencing using next-generation technologies provides resources for gene expression profiling studies as well as simultaneous identification of mutations, sequence aberrations, alternative splice variants and RNA editing events (Morozova et al. 2009). The present study focused on the application of next-generation sequencing to transcriptome analysis of $V$. alginolyticus and further understanding of the mechanisms affecting bacterial adhesion. One of the most important aspects in transcriptome analysis is to associate individual sequences and related expression information with biological functions. These annotations provide a resource for further functional characterization of genes during the adhesion of $V$. alginolyticus, and further understanding of how the adhesion process may be influenced by environmental factors.

In the present study, we obtained adhesion affected models through culturing $V$. alginolyticus under stress conditions including $\mathrm{Cu}^{2+}, \mathrm{Pb}^{2+}, \mathrm{Hg}^{2+}$ and low $\mathrm{pH}$. According to our results, a significant decline in adherence was observed in all stressed groups, while the low $\mathrm{pH}$ treated group displayed the lowest adhesion. Interestingly, the results of DEGs analysis showed that low $\mathrm{pH}$ treated group yielded the most DEGs, followed by $\mathrm{Cu}^{2+}$ treated group, $\mathrm{Pb}^{2+}$ treated group and $\mathrm{Hg}^{2+}$ treated group, which was consistent with the adhesion phenotype of these groups. These results suggest that these DEGs may be related to bacterial adhesion. Furthermore, the 213 common regulated genes might play important roles in bacterial adhesion, dissecting which may add to understanding of the mechanisms underlying the regulation of 
adhesion in $V$. alginolyticus. In addition, these 213 common regulated genes were sensitive to the environmental factors tested, and so further analysis of these may reveal how the adhesion process is influenced by environmental factors. Notably, only one upregulated gene was found in all four treated groups, which encodes the type III secretion protein SctT. It is well known that type III secretion systems delivers many structurally diverse bacterial virulence proteins into plant and animal cells to modulate host cellular functions. How the type III secretion system may participate in influencing the adhesion of $V$. alginolyticus has not yet been reported. Therefore, further research is still necessary.

GO analysis indicated that many of the DEGs were related to biological processes correlated with bacterial adhesion and environmental stress responses, such as "cell motility", "response to chemical stimulus" and "establishment of localization". KEGG analysis suggested that many of the DEGs were concentrated in biological regulation, cellular process, localization, establishment of localization and metabolic processes, which meant the stress treatments could affect intricate biological process (including adhesion) of $V$. alginolyticus.

Among the 164 KEGG pathways, some pathways may be closely related to the adhesion process. For example, "Two-component system", "Bacterial chemotaxis" and "Flagellar assembly" can be closely related to the motility and adherence of bacteria (Mello et al. 2007; Philippe et al. 2000; Victor et al. 2004; Takekawa et al. 2014; Wang et al. 2000; Meadows et al. 1971; DeBoer et al. 1975; Kawagishi et al. 1995; Bordas et al. 1996, 1998; Belas et al. 1982). The process of adhesion of bacteria is connected to the movement of bacteria in response to a chemical stimulus. Chemical gradients are sensed through multiple transmembrane receptors, called methylaccepting chemotaxis proteins (MCPs), which vary in the molecules that they detect. These receptors may bind attractants or repellents directly or indirectly through interaction with proteins of the periplasmic space. The signals from these receptors are transmitted across the plasma membrane into the cytosol, where the two-component system is activated. The twocomponent system then induces tumbling by interacting with the flagellar switch protein FliM, inducing a change from counter-clockwise to clockwise rotation of the flagellum. Change in the rotation state of a single flagellum can disrupt the entire flagella bundle and cause a tumble. Interestingly, the levels of "Bacterial chemotaxis" genes among different stressed groups was ranked low $\mathrm{pH}$ treated group $>\mathrm{Cu}^{2+}$ treated group $>\mathrm{Pb}^{2+}$ treated group $>\mathrm{Hg}^{2+}$ treated group, which was consistent with the extent their adhesion decreased. These results reinforce the hypothesis that the DEGs found in the present study might play important roles in bacterial adhesion.

To our knowledge, this is the first report of the application of next generation sequencing technology to provide an annotated overview of $V$. alginolyticus gene expression and identification of adhesion related DEGs. Taken as a whole, the present study demonstrates that chemical stress of $V$. alginolyticus induces changes in gene expression profiles. This is, to our knowledge, the first analysis of differentially expressed genes in $V$. alginolyticus after chemical stress. Our results demonstrated that some of the changed genes correlate with changes in bacterial adhesion, which validated previous results and offered new clues for further understanding of the mechanism(s) underlying the regulation of adhesion by $V$. alginolyticus and how this may be influenced by environmental factors. However, further research is now needed to further define the significance of these findings.

Acknowledgments This work was supported by grants from The National Natural Science Foundation of China under contract No. 31272699, 31272669 and 31202030, Science and Technology Program of Xiamen under contract No. 3502Z20133016, Science and Technology Program of Ocean \& Fisheries Bureau of Xiamen under contract No. 201357, Science and Technology Program of Xiamen Southern Oceanographic Center under contract No. 14CZP032HJ06 and 14PYY050SF03.

Conflict of interest The authors declare that they have no competing interests.

Open Access This article is distributed under the terms of the Creative Commons Attribution License which permits any use, distribution, and reproduction in any medium, provided the original author(s) and the source are credited.

\section{References}

Arnvig KB, Comas I, Thomson NR, Houghton J, Boshoff HI, Croucher NJ, Rose G, Perkins TT, Parkhill J, Dougan G, Young DB (2011) Sequence-based analysis uncovers an abundance of non-coding RNA in the total transcriptome of 
Mycobacterium tuberculosis. PLoS Pathog 7(11): e1002342

Balebona MC, Moriñigo MA, Faris A, Krovacek K, ManssonI Bordas MA, Borrego JJ (1995) Influence of salinity and pH on the adhesion of pathogenic Vibrio strains to Sparus aurata skin mucus. Aquaculture 132:113-120

Balebona MC, Andreu MJ, Bordas MA, Zorrilla I, Moriñigo MA, Borrego JJ (1998) Pathogenicity of Vibrio alginolyticus for cultured gilt-head sea bream (Sparusaurata L.). Appl Environ Microbiol 64:4269-4275

Belas MR, Colwell RR (1982) Adsorption kinetics of laterally and polarly flagellated Vibrio. J Bacteriol 151:1568-1580

Bisharat N, Bronstein M, Korner M, Schnitzer T, Koton Y (2013) Transcriptome profiling analysis of Vibrio vulnificus during human infection. Microbiology 159(Pt 9): 1878-1887

Bordas MA, Balebona MC, Zorrilla I, Borrego JJ, Moriñigo MA (1996) Kinetic of adhesion of selected fish-pathogenic Vibrio strains to skin mucus of gilt-head sea bream (Sparus aurata L). Appl Environ Microbiol 62:3650-3654

Bordas MA, Balebona MC, Zorrilla I, Borrego JJ, Moriñigo MA (1998) Chemotaxis of pathogenic Vibrio strains towards mucus surfaces of gilt-head sea bream (Sparus aurata L). Appl Environ Microbiol 64:1573-1575

Bradford NM (1976) A rapid and sensitive method for the quantification of microgram quantities of protein utilizing the principle of protein-dye binding. Anal Biochem 72: 248-254

Carli A, Pane L, Casareto L, Bertone S, Pruzzo C (1993) Occurrence of Vibrio alginolyticus in Ligurian coast rock pools (Tyrrhenian Sea, Italy) and its association with the copepod Tigriopus fulvus (Fisher 1860). Appl Environ Microbiol 59:1960-1962

Chen Q, Yan Q, Wang K, Zhuang Z, Wang X (2008) Portal of entry for pathogenic Vibrio alginolyticus into Pseudosciaene crocea and characteristic of bacterial adhesion to the mucus. Dis Aquat Org 80:181-188

DeBoer WE, Golten G, Scheffers WA (1975) Effects of some physical factors on flagellation and swarming of Virio alginolyticus. Neth J Sea Res 9:197-213

Kawagishi I, Maekawa Y, Atsumi T, Homma M, Imae Y (1995) Isolation of the polar and lateral flagellum-defective mutants in Vibrio alginolyticus and identification of their flagellar driving energy sources. J Bacteriol 177:51585160

Lee KK (1995) Pathogenesis studies on Vibrio alginolyticus in the grouper, Epinephelus malabaricus, Bloch et Schneider. Microb Pathog 19:39-48

Lee KK, Yu SR, Yang TI, Liu PC, Chen FR (1996) Isolation and characterization of Vibrio alginolyticus isolated from diseased kuruma prawn, Penaeusjaponicus. Lett Appl Microbiol 22:111-114

Lenz G, Doron-Faigenboim A, Ron EZ, Tuller T, Gophna U (2011) Sequence features of E. coli mRNAs affect their degradation. PLoS One 6(12):e28544

Li RQ, Yu C, Li Y, Lam TW, Yiu SM, Kristiansen K, Wang J (2009) SOAP2: an improved ultrafast tool for short read alignment. Bioinformatics 25(15):1966-1967

Lin YJ, Ou JM, Dong XP, Chen W (2001) Etiological study of Vibrio alginolyticus. Strait J Prev Med 7(1):45-46
Liu PC, Chen YC, Lee KK (2001) Pathogenicity of Vibrio alginolyticus isolated from diseased small abalone Haliotis diversicolor supertexta. Microbios 408:71-77

Marioni JC, Mason CE, Mane SM, Stephens M, Gilad Y (2008) Rna-Seq: an assessment of technical reproducibility and comparison with gene expression arrays. Genome Res 18(9):1509-1517

Meadows PS (1971) The attachment of bacteria to solid surfaces. Arch Mikrobil 75:374-381

Mello BA, Tu YH (2007) Effects of adaptation in maintaining high sensitivity over a wide range of backgrounds for Escherichia coli chemotaxis. Biophys J 92(7):2329-2337

Morozova O, Hirst M, Marra MA (2009) Applications of new sequencing technologies for transcriptome analysis. Annu Rev Genomics Hum Genet 10:135-151

Mortazavi A, Williams BA, McCue K, Schaeffer L, Wold B (2008) Mapping and quantifying mammalian transcriptomes by RNA-Seq. Nat Methods 5:621-628

Pfaffl MW, Horgan GW, Dempfle L (2002) Relative expression software tool (REST) for group-wise comparison and statistical analysis of relative expression results in real-time PCR. Nucleic Acids Res 30:e36

Philippe C, Michael S, Stanislas L (2000) An ultrasensitive bacterial motor revealed by monitoring signaling proteins in single cells. Science 287(5458):1652-1655

Qin YX, Yan QP, Su YQ, Liu LM, Li XG (2013) Disruption of chemotactic motility correlative genes influences multiple cellular processes and virulence in Vibrio harveyi. Acta Oceanol Sin 32(8):55-60

Reddy JS, Kumar R, Watt JM, Lawrence ML, Burgess SC, Nanduri B (2012) Transcriptome profile of a bovine respiratory disease pathogen: mannheimia haemolytica PHL213. BMC Bioinformatics 13(Suppl 15):S4

Sharma CM, Hoffmann S, Darfeuille F, Reignier J, Findeiss S, Sittka A, Chabas S, Reiche K, Hackermüller J, Reinhardt R, Stadler PF, Vogel J (2010) The primary transcriptome of the major human pathogen Helicobacter pylori. Nature 464(7286):250-255

Simon DF, Domingos RF, Hauser C, Hutchins CM, Zerges W, Wilkinson KJ (2013) Transcriptome sequencing (RNAseq) analysis of the effects of metal nanoparticle exposure on the transcriptome of Chlamydomonas reinhardtii. Appl Environ Microbiol 79(16):4774-4785

Speare DJ, Mirsalimi SM (1992) Pathology of the mucous coat of trout skin during an erosive bacterial dermatitis: a technical advance in mucous coat stabilization for ultra structural examination. J Comp Pathol 106:201-211

Takekawa N, Kojima S, Homma M (2014) Contribution of many charged residues at the stator-rotor interface of the $\mathrm{Na}^{+}$-driven flagellar motor to torque generation in Vibrio alginolyticus. J Bacteriol 196(7):1377-1385

Thune RL, Stanley LA, Cooper RK (1993) Pathogenesis of gram-negative bacterial infections in warm water fish. Annu Rev Fish Dis 3:37-68

Victor S, Tso WW (2004) Receptor clustering and signal processing in E. coli chemotaxis. Trends Microbiol 12(12): $569-576$

Wang XH, Leung KY (2000) Biochemical characterization of different types of adherence of Vibrio species to fish epithelial cells. Microbiology 146:989-998 
Wang J, Su YQ, Zhang ZX (2001) Bacterial pathogenetic biology of cultured Pseudosciaena crocea in southern Fujian. J Xiamen Univ (Nat Sci) 40(1):85-91

Xie ZY, Ke SW, Hu CQ, Zhu ZX, Wang SF, Zhou YC (2013) First characterization of bacterial pathogen, Vibrio alginolyticus, for Porites andrewsi white syndrome in the south China Sea. PLoS One 8(9):e75425

Xu Q, Dziejman M, Mekalanos JJ (2003) Determination of the transcriptome of Vibrio cholerae during intraintestinal growth and midexponential phase in vitro. PNAS 100(3):1286-1291

Yan QP, Wang J, Su YQ (2001) Studies on Vibriosis in cagedcultured Pseudosciaena crocea (Richardson). J. Jimei Univ (Nat Sci) 6(3):191-196
Yan QP, Chen Q, Ma S, Zhuang ZX, Wang XR (2006) Characteristics of adhesion of Vibrio alginolyticus to the skin mucus of Pseudosciaena crocea. Acta Oceanol Sin 28(6):100-105

Yan QP, Chen Q, Ma S, Zhuang ZX, Wang XR (2007) Characteristics of adherence of pathogenic Vibrio alginolyticus to the intestinal mucus of large yellow croakers (Pseudosciaena crocea). Aquaculture 269:21-30

Yang L, Zhou D, Liu X, Han H, Zhan L, Guo Z, Zhang L, Qin C, Wong HC, Yang R (2009) Cold-induced gene expression profiles of Vibrio Parahaemolyticus: a time-course analysis. FEMS Microbiol Lett 291(1):50-58 